\title{
Effects of Ascorbic Acid, Alpha-Tocopherol and Allopurinol on Ischemia-Reperfusion Injury in Rabbit Skeletal Muscle: An Experimental Study
}

\author{
Bilgehan Erkut ${ }^{1}$, Ahmet Özyazıcıoğlu ${ }^{2}$, Bekir Sami Karapolat ${ }^{1}$, Cevdet Uğur \\ Koçoğulları ${ }^{3}$, Sait Keles ${ }^{4}$, Azman Ateş ${ }^{1}$, Cemal Gundogdu ${ }^{5}$, Hikmet Kocak ${ }^{1}$ \\ ${ }^{1}$ Department of Cardiovascular Surgery, Atatürk University Medical Faculty, Erzurum, Turkey. \\ ${ }^{2}$ Department of Cardiovascular Surgery, Yüksek İhtisas Hospital, Bursa, Turkey. ${ }^{3}$ Department of \\ Cardiovascular Surgery, Afyon Kocatepe University Medical Faculty, Afyon, Turkey. ${ }^{4}$ Department \\ of Biochemistry, Atatürk University Medical Faculty, Erzurum, Turkey. ${ }^{5}$ Department of Pathology, \\ Medical Faculty of Atatürk University, Erzurum, Turkey.
}

\section{Abstract}

Purpose: Ischemia reperfusion injury to skeletal muscle, following an acute arterial occlusion is important cause of morbidity and mortality. The aim of the present study was to determine and evaluate the effects of ascorbic acide, alpha-tocopherol and allopurinol on ischemia reperfusion injury in rabbit skeletal muscle.

Methods: Forty-eight New Zealand white rabbits, all male, weighing between 2.5 to 3.0 (mean 2.8) $\mathrm{kg}$, were used in the study. They were separated into four groups. Group I was the control group without any drugs. The other groups were treatment groups (groups II, III, and IV). Group II rabbits administrated $50 \mathrm{mg} / \mathrm{kg}$ ascorbic acide and $100 \mathrm{mg} / \mathrm{kg}$ alpha-tocopherol 3 days prior to ischemia, group III rabbits received $50 \mathrm{mg} / \mathrm{kg}$ allopurinol 2 days prior to ischemia, and group IV rabbits were administrated both $50 \mathrm{mg} / \mathrm{kg}$ ascorbic acide, $100 \mathrm{mg} / \mathrm{kg}$ alpha-tocopherol 3 days prior to ischemia and $50 \mathrm{mg} / \mathrm{kg}$ allopurinol 2 days prior to ischemia. Two hours ischemia and 2 hours reperfusion were underwent to the treatment groups. At the end of the reperfusion periods, muscle samples were taken from rectus femoris muscle for determination of superoxide dismutase, catalase and glutathione peroxidase activities as antioxidant enzymes, and malondialdehyde as an indicator of lipid peroxidation and xanthine oxidase levels as source hydroxyl radical. Besides, histopathological changes (edema, inflammation, ring formation and splitting formation) were evaluated in the muscle specimens.

Results: In the treatment groups; superoxide dismutase (U/mgprotein), catalase (U/mgprotein), and glutathione peroxidase (U/mgprotein) levels increased, malondialdehyde (nmol/mgprotein) and xanthine oksidase (mU/mgprotein) levels decreased compared to control I $(p<0.05)$. Increase of superoxide dismutase, catalase, and glutathione peroxidase levels were the highest and decrease of malondialdehyde and xanthine oxidase levels were the highest in group IV compared to groups II and III, but no significant as statistically. Also amount of cellular injury in group II, III, and IV were lower than group I.

Conclusions: Antioxidant medication may help lowering ischemia reperfusion injury. In our study, all drug medications are shown to be able to have an effective role for preventing ischemia reperfusion injury. Moreover, ascorbic acide + alphatocopherol + allopurinol group (group IV) may have a beneficial effect to decrease the local and systemic damage due to ischemia-reperfusion injury.

Keywords: Ischemia-reperfusion injury, antioxidant agents, ascorbic acid, alpha-tocopherol, allopurinol

\section{Introduction}

Ischemia-reperfusion (I/R) injury is an important adverse clinical outcome in a wide range of vascular conditions and surgical interventions including stroke, transplantation, cardiopulmonary bypass, trauma, and abdominal aortic aneurysm repair. It is a complex and serious condition and may life-threatening (1). Experimental studies have shown that the tissue-destructive effects of $\mathrm{I} / \mathrm{R}$ injury are mediated by free oxygen radicals $\left(\mathrm{H}_{2} \mathrm{O}_{2}, \mathrm{O}_{2}^{-}, \mathrm{OH}^{-}\right)$, which damage cellular components and they cause lipid peroxidation of cellular membranes and generate more free radicals (FRs) in a self-propagating cycle, leading to cell death by necrosis (1-3).

Correspondence: Bilgehan Erkut, Assist Prof, Atatürk Bulvari, Eda Apartmani Palandoken Polikliniği Üstü, Kat: 3, No: 3, 25080 Yenişehir, Erzurum, Türkiye. Tel: (+90 533) 74510 06; Fax: (+90 442) 31663 40; Email: bilgehanerkut@yahoo.com

Copyright in this article, its metadata, and any supplementary data is held by its author or authors. It is published under the Creative Commons Attribution By licence. For further information go to: http://creativecommons.org/licenses/by/3.0/. 
The physiopathology of I/R injury is a complex cascade of events starting from the point of release of FRs followed by lipid peroxidation that ends by procuding substances such as malonyldialdehyde (MDA) $(4,5)$. The determination of MDA can be used as a marker of FR formation (6). During ischemia, ATP production is diminished related to the limited oxygen availability. Secondly, the changes in membrane ion gradients cause an influx of calcium in damaged membranes. This leads to an elevation of the cytosolic calcium concentration that activates proteases capable of transforming xanthine dehydrogenase to xanthine oxidase (XO). During reperfusion, the provided molecular oxygen is converted to superoxide radicals by XO (6). There is evidence that XO levels are elevated during ischemia $(6,7)$.

The first line defence mechanism includes antioxidant enzymes such as superoxide dismutase (SOD), catalase (CAT) and glutathione peroxidase (GPx) which they are the enzymatic part represented by FR scavenger enzymes (8). These enzymes catalyse the conversion of FRs into less reactive species. Another mechanism is the nonenzymatic part including a large number of natural or synthetic antioxidant compounds, which have the ability to inhibit the oxidative damage by scavenging the highly destructive FR species (9).

Ascorbic acide is a well-known antioxidant agent and can protect the endothelium from direct injury by oxidants, including $\mathrm{H}_{2} \mathrm{O}_{2}$, and prevent microvascular dysfunction $(10,11)$. We and others have also shown that ischaemia-reperfusion injury is reduced by the administration of ascorbic acide (10-12). Alpha-tocopherol is a potent antioxidant and shown that it prevents reperfusion injury in miscellaneous tissue (13). Allopurinol is a XO inhibitor that prevents the generation of FRs and may play a role in the protection of the cells during cerebral ischemia. Previous studies have indicated that allopurinol can improve the tissue energy metabolism during reperfusion after ischemia $(14,15)$.

A number of authors have examined the role of FRs species in ischemic damage to skeletal muscle and experimentally, and the effect of FR scavengers have been evaluated in skeletal muscle $(16,17)$. Besides, in many studies, the antioxidant activity was shown the roles of ascorbic acide, alphatocopherol and allopurinol in $\mathrm{I} / \mathrm{R}$ injury through biochemical enzyme studies in addition to histopathological studies (18-21). But, according to our knowledge, there was no report to show the effects of ascorbic acide, alpha-tocopherol and allopurinol on reducing reperfusion injury in muscle of rabbit.

The aim of this study was to determine the protective effect of the ascorbic acide, alphatocopherol and allopurinol as antioxidant agents against FRs in extremity ischemia and reperfusion. For this purpose, we measured SOD, CAT, GPx and MDA, XO levels, and evaluated as histopathologically in rabbit muscle in ischemia reperfusion model. Our findings suggest that all drug groups, especially group IV, reduces I/R injury.

\section{Materials and Methods}

The experiment was performed in compliance with the Principles of Laboratory Animal Care formulated by the National Institutes of Health. The experiment and animal care protocol, and all procedures were approved by the Local Ethics Committee in Animal Experiments.

\section{Animals}

Fourty-eight rabbits were used as subjects in our study. Male adult New Zealand type rabbits weighing 2,500-3,000 g $(2,610 \pm 1,122 \mathrm{~g})$ were kept in a light-controlled room with a 12:12-h light-dark cycle; temperature $\left(22 \pm 0.5^{\circ} \mathrm{C}\right)$ and relative humidity $(65 \%-70 \%)$ were kept constant. Animals received a standard rabbit diet and water and libitum. They had not been used in priory another study and they had not been given a drug regularly, in addition they had not a disease, previously. The rats were deprived of food for $12 \mathrm{~h}$ before the experiment but had free access to water. The subjects were inserted 22 no branul through ear veins. Experiments were carried out under sterile conditions and antibiotic prophylaxis with cefazolin sodium (30 mg/kg intramuscularly, single preoperative dose) was given. Isotonic $\mathrm{NaCl}$ solution was given intravenously at the rate of $3 \mathrm{ml} / \mathrm{kg} / \mathrm{h}$. During all experimental manipulations, to prevent the effects of hypothermia and to provide the stability of hemodynamic parameters, the body temperature was maintained at $37.2^{\circ} \mathrm{C}$ with a rectal probe. For this, animals were placed on an operating table with thermoregulatory, and was used heat pad.

\section{Artificial respiration}

The rabbits were shaved from abdomen to leg. The surgical area was painted with batticon. Surgical 
area was cleaned and draped. The rabbits were intubated via endotracheal cannulation (16-G Vasofix, B. Braun Melsungen, AG, and Germany). Tidal volume and respiratory rate were adjusted to $10 \mathrm{ml} / \mathrm{kg}$ (3 $\mathrm{ml}$ for an average of 250-300 g subject) and 60 times per minute, respectively. Ventilator (Ugo Basile, Biological Research Apparatus, Comerio, and Varesee, Italy) was used for artificial respiration.

\section{Experimental groups}

Before starting the experimental protocols, rabbits were divided into four groups of twelve animals. The first group was the control group (group I) without any treatment, the treatment groups were the group II, which was medicated intravenous with $50 \mathrm{mg} / \mathrm{kg}$ ascorbic acide (Redoxan $500 \mathrm{mg}$ ampule, Roche, Germany) and intramuscular with $100 \mathrm{mg} / \mathrm{kg}$ alpha-tocopherol ( $\alpha$-T; Evigen $300 \mathrm{mg}$ ampule, Aksu Farma, Turkey) for 3 days prior experiment, the group III, which was medicated with $50 \mathrm{mg} / \mathrm{kg}$ allopurinol (Urikoliz $300 \mathrm{mg}$, Ilsan, Turkey) for 2 days via per oral prior experiment, and the group IV, which was medicated with both ascorbic acide + alpha-tocopherol + allopurinol. The dosage and timing of each antioxidant were based on our preliminary data on the metabolism of the drugs, and on published data, which determined the peak serum concentrations of the drugs at the time reperfusion was initiated (22-25). The protective effects against increasing of lipid peroxidation caused by $\mathrm{I} / \mathrm{R}$ were shown in rats treated with different dosages (range, 30-100 mg/kg) of ascorbic acide (22). In light of these past studies, we used $50 \mathrm{mg} / \mathrm{kg}$ of ascorbic acide as the dosage in our study. Dosage of alpha-tocopherol and allopurinol were chosed on on the basis of earlier studies $(24,26,27)$. In experiment day, all animals were performed ischemia for 2 hours, and then performed reperfusion for 2 hours. Hoballah's I/R model was used with direct occlusion of femoral artery and vein occlusions in the medial part of rectus femoris muscle (28).

\section{Surgical method}

The rabbits were anesthetized with intramuscular injection of $15 \mathrm{mg} / \mathrm{kg}$ ketamine hydrochloride (Ketalar; Pfizer, Istanbul, Turkey) and $2 \mathrm{mg} / \mathrm{kg}$ xylazine hydrochloride (Rompun, Bayer, Turkey) before the surgical procedure. Longitudinal incision was performed in venteromedial of right thigh.
After the femoral area exploration, we reached to the rectus femoris muscle. Heparin of $400 \mathrm{U} / \mathrm{kg}$ (Liquemine, Roche, Brazil) was given via ear vein. The medial part of rectus femoris muscle was cut and separated from surrounding tissues. The I/R model was constituted by using the direct occlusion procedure as the study of Hoballah (Fig.1) (28). We exposed the muscle to ischemia for 2 hours. During the ischemic waiting period, incision was closed and the rabbits were freed. At the end of the ischemic period, was applied intraperitoneally ketamine hydrochloride and incision was opened, again. Microvascular clamps were removed and the wounds were closed. It was exposed to reperfusion for 2 hours. At the end of the reperfusion, muscle tissue samples were collected for biochemical and histopathological examination after the incision was opened. The muscle pieces from proximal and distal were anastomozed with one another. The femoral area was closed with silk suture. During these surgical interventions intervals, they were given same sort analgesics.

\section{Biochemical assay}

SOD, CAT, GPx, XO, MDA were detected in muscle tissue cuts. Each tissue was stocked in a separate bowl at $-80{ }^{\circ} \mathrm{C}$ till analysis. Tris tampon of $10 \mathrm{ml}$ was added into each one gram of frozen tissues. Homogenates are to be centrifuged at $10.000 \times \mathrm{G}$ for 10 minutes after homogenization. Supernatants were kept in stock at $-80{ }^{\circ} \mathrm{C}$ till analysis. Analysis of tissue samples was carried out spectrophotometrically as below. Results were expressed as units per miligram protein for SOD, CAT, GPX, and nanomoles per milligram for MDA and miliunits per milligram for $\mathrm{XO}$.

Tissue SOD Assay: The method is based on the inhibition of nitroblue tetrazolium (NBT) reduction by the xanthine-XO system as a superoxide generator by using Yi-Sun method (29). Study solution was prepared by mixing xanthine $(0.3 \mathrm{mmol} / \mathrm{l})$, ethylenediaminetetraacetate (EDTA) $(0.6 \mathrm{mmol} / 1)$, NBT $(0.15 \mathrm{mmol} / \mathrm{l})$, sodium carbonate $\left(\mathrm{Na}_{2} \mathrm{CO}_{3}\right)$ (400 mmol/1), bovine serum albumin ( $1 \mathrm{~g} / \mathrm{l})$. Study solution of $2850 \mathrm{ul}, 100 \mathrm{UL}$ supernatan, $100 \mathrm{ul}$ distilled water and $50 \mathrm{UL} \mathrm{XO} \mathrm{(5} \mathrm{U/L)} \mathrm{were} \mathrm{incu-}$ bated for 25 minutes at $20^{\circ} \mathrm{C}$. Following 30 seconds, absorbance was recorded. One unit is the amount of SOD that inhibits the rate by $50 \%$.

Tissue CAT assay: Catalase activity was assayed according to the methods of Cohen et al. (30) 


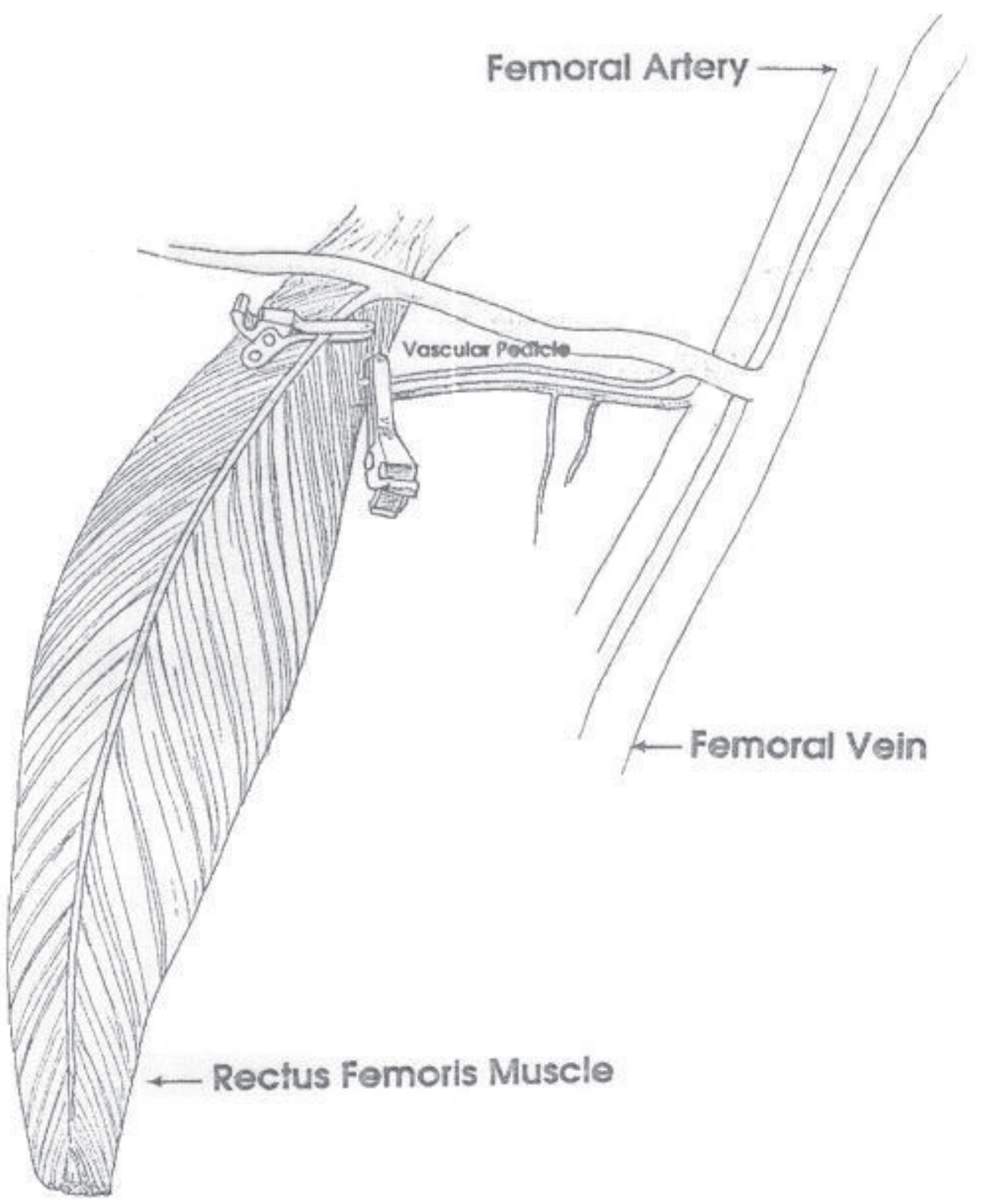

Figure 1. Occlusion appearance of two vascular systems of rectus femoris muscle (direct occlusion) as described by Hoballah.

To a $100 \mu \mathrm{L}$ aliquot of tissue extract, ethanol was added to a concentration of $0.17 \mathrm{~mol} / \mathrm{L}$ (10 $\mu \mathrm{L}$ ethanol $/ \mathrm{mL}$ ) and samples were incubated in an ice bath for $30 \mathrm{~min}$. After $30 \mathrm{~min}, 10 \%$ Triton $\mathrm{X}-100$ was added to a final concentration of $1 \%$ and samples were kept at room temperature. Reactions were performed at room temperature. The enzyme-catalysed decomposition of $\mathrm{H}_{2} \mathrm{O}_{2}$ was measured. In a tube containing $200 \mu \mathrm{L}$ phosphate buffer and $50 \mu \mathrm{L}$ tissue extract, $1 \mathrm{~mL}$ of $6.0 \mathrm{mmol} / \mathrm{L} \mathrm{H}_{2} \mathrm{O}_{2}$ (in phosphate buffer) was added and mixed thoroughly. The reaction was stopped after exactly $3 \mathrm{~min}$ by the addition of $100 \mu \mathrm{L}$ of $6 \mathrm{~mol} / \mathrm{L} \mathrm{H}_{2} \mathrm{SO}_{4}$. The excess $\mathrm{H}_{2} \mathrm{O}_{2}$ was measured by reacting it with a standard excess of $\mathrm{KMnO}_{4}$ and then measuring the residual $\mathrm{KMnO}_{4}$ spectrophotometrically at $480 \mathrm{~nm}$ within 30-60 s using 1.0 absorbance unit for standard $\mathrm{KMnO}_{4}$.

Tissue GPx assay: GPx catalyzes oxidation of glutathione (GSH) by using hydrogen peroxide. The activity of GPx was determined by the Beutler method (31). Briefly, solutions of tris- $\mathrm{HCl}$ $(1000 \mathrm{mmol} / \mathrm{l})$, EDTA (5 mmol/l) $(\mathrm{pH}=8.0), \mathrm{GSH}$ (100 mmol/l), GSH reductase $(10 \mathrm{U} / \mathrm{ml})$, nicotinamide adenine dinucleotide phosphate (NADPH) ( $2 \mathrm{mmol} / \mathrm{l})$, and t-butil hydroperoxide $(7 \mathrm{mmol} / \mathrm{l})$ were incubated with $10 \mathrm{UL}$ hemolysate for 
10 minutes at $37{ }^{\circ} \mathrm{C}$. Decrease in NADPH was foolewed spectrophotometically at $340 \mathrm{~nm}$.

Tissue MDA assay: Thiobarbituric acid (TBA) reactive substances, MDA and product of fatty acid peroxidation, reacts with TBA to form a colored complex that has maximum absorbance at $532 \mathrm{~nm}$ by Ohkawa method (32). 200 ul sodium dodecyl sulfate (8.1\%), $1.5 \mathrm{ml}$ acetic acid (20\%), $1.5 \mathrm{ml}$ TBA $(0.8 \%), 0.6 \mathrm{ml}$ distilled water were mixed by 200 UL tissue homogenate (10\%) and heated in boiling water for 60 minutes. After cooling, $1 \mathrm{ml}$ distilled water and $5 \mathrm{ml}$ butanol/pyrimidine (15:1) were added. After centrifuging at $4000 \mathrm{rpm}$ for 10 minutes, absornance of the supernatant was read at $532 \mathrm{~nm}$.

Tissue XO assay: XO activity was determined spectrophotometrically by the method of Hashimoto (33), based on the formation of uric acid from xanthine at $293 \mathrm{~nm}$.

\section{Histopathological examination}

The muscle biopsy samples of the subjects were fixed in neutral formalin solution (3\%) for 24 hours. Paraffin blocks were prepared after biopsy samples were exposed to routine tissue examination. Later 1 to 2 micro hematoxylin-eosin (HE) cuts of paraffin blocks were prepared. Light microscopy findings were scored as 0 to +3 which corresponds to no change, mild, moderate and severe changes, respectively. Assessments were made for interstitial edema, inflammation, splitting formation and ring formation in tissues through the use of Nikon optiphot-2 microscope.

\section{Statistical analysis}

All the results were obtained as mean \pm SEM for each study group. All statistical analyses were carried out using SPSS 10.0 statistical software (SPSS Inc, Chicago, IL). The significance of differences between the groups was assessed using the Nonparametric analyses with Mann-Whitney U-test, and The Kruskal-Wallis test was used to compare group medians for histopathological. Statistical significance was set up $p<0.05$.

\section{Results}

\section{Biochemical evaluation}

SOD, CAT, and GPx levels were measured in skeletal muscle after 2 hours reperfusion, and the levels increased in the treatment groups compared to control group (from $0,17 \pm 0,02$ to $0,23 \pm 0,02$, $0,23 \pm 0,03$ and $0,25 \pm 0,04$, respectively for SOD; from $6,74 \pm 1,00$ to $9,02 \pm 0,60,8,22 \pm 1,35$ and $9,09 \pm 1,16$, respectively for CAT; from 18,52 \pm 2,26 to $22,48 \pm 2,38,23,06 \pm 2,34$ and $25,67 \pm 3,72$, respectively for GPx) (Fig. 2), and it was significant as statistically $(p<0.05)$. However, there was no a statistically significant among group II, III, and IV in terms of the increasing in enzymes levels. XO levels in the skeletal muscle were found to be higher in the control group. However, in treatment groups lowered (from 2,86 $\pm 0,35$ to $2,19 \pm 0,34,1,94 \pm$ 0,41 and $1,02 \pm 0,32$, respectively) the levels of XO during ischemia and reperfusion (Fig. 3). Tissue MDA levels were decreased (from $0,38 \pm 0,13$ to $0,12 \pm 0,04,0,13 \pm 0,07$ and $0,10 \pm 0,02$, respectively) in the treatment group compared to the control group. The results of MDA assays are shown in Figure 3.

\section{Histopathological evaluation}

Cell infiltration, edema, splitting and ring formations were evaluated for 4 groups. There was a significant difference in terms of pathological parameters between treatment groups and control group as histopathological scores $(p<0.05)$. Figure 4 shows markedly ring formation, splitting formation, interstitial edema, and neutrophil cell infiltration in control group after 2 hour reperfusion. In treatment groups ring formation, splitting formation, interstitial edema, and neutrophil cell infiltration decreased markedly compared to control group. Although ring formation was rare in treatment groups, there was not a difference among 3 treatment groups $(p>0.05)$. Splitting formation, interstitial edema and neutrophil cell infiltration were less determined in treatment groups $(p<0.05)$. When treatment groups were compared to each other, it was found that splitting formation, interstitial edema and neutrophil cell infiltration was less in group IV $(p<0.05)$.

\section{Discussion}

Because skeletal muscle is more resistant to the ischemia, we applied total skeletal muscle ischemia model in this study. The transformation of xanthine dehydrogenase into XO during FRs constitution is slower in skeletal muscle, which explains why skeletal muscle is more resistant to ischemia $(28,34,35)$. Recently advances in the understanding of reperfusion injury and the pharmacology of 

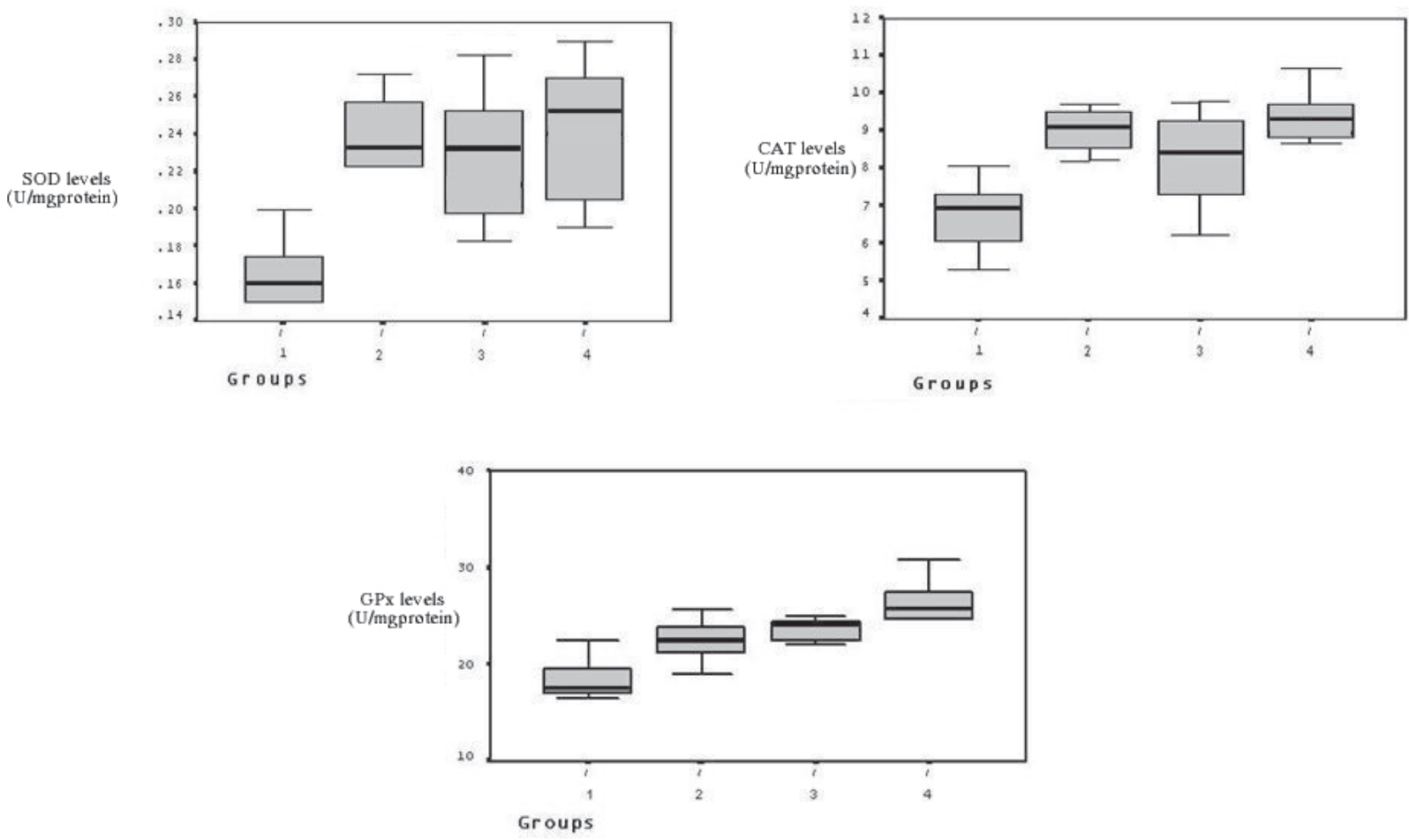

Figure 2. Between groups SOD, CAT, and GPx enzyme levels. Increased SOD, CAT and GPx levels in treatment groups compared to control group.

antioxidants have made the interruption of reperfusion injury clinically promising and FR mediated tissue injury can be limited by the use of antioxidant therapy and several studies have suggested a positive role for antioxidant therapy in skeletal muscle reperfusion injury $(36,37)$.

It is well recognized that ischaemia followed by reperfusion in skeletal muscle represents an important clinical problem in many vascular diseases and musculoskeletal trauma. The significant mortality and morbidity can be due to compartment syndrome, rhabdomyolysis, renal failure, limb loss, systemic inflammatory syndrome and respiratory and mesenteric injuries. It has been emphasized the importance of ischaemia duration as a progressive increase of ultrastructural lesions takes place between 2- and 7-h ischaemia insult in skeletal muscular tissues (38). Two hours after ischaemia, it is already possible to identify, with histochemical analysis, small muscular lesions which become severe according to the ischaemia duration (39). Regarding reperfusion injury, several reports have
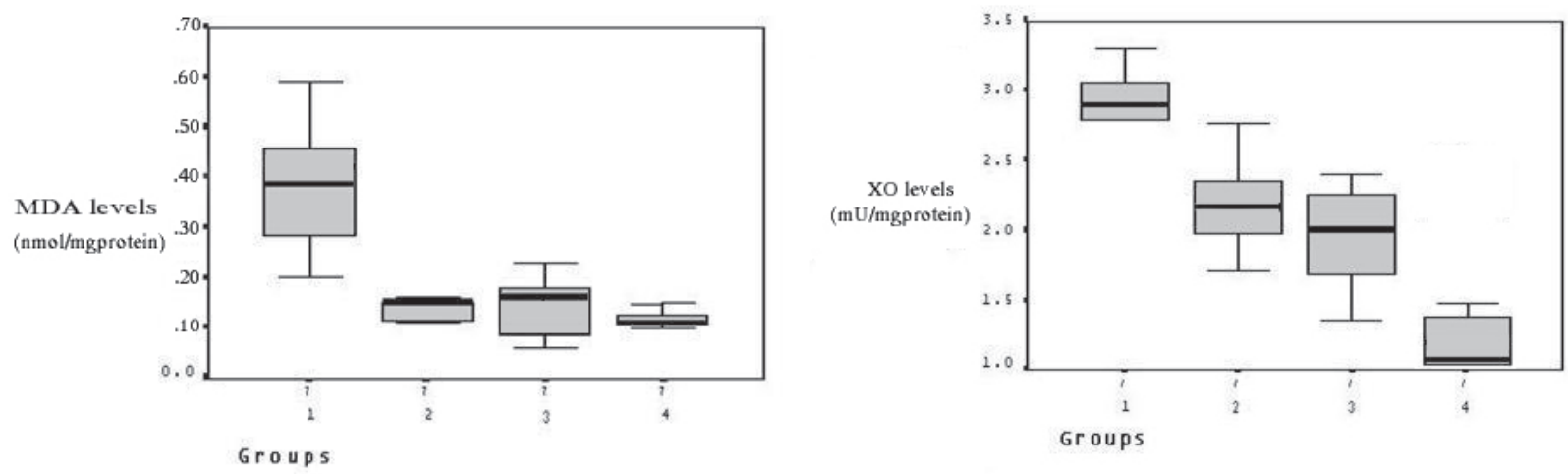

Figure 3. Between groups MDA and XO enzyme levels. Decreased MDA and XO levels in treatment groups compared to control group. SOD; superoxide dismutase, CAT; Catalase, GPx; glutathione peroxidase, MDA; malonyldialdehyde, XO; xanthine oxidase, AP: Allopurinol. 

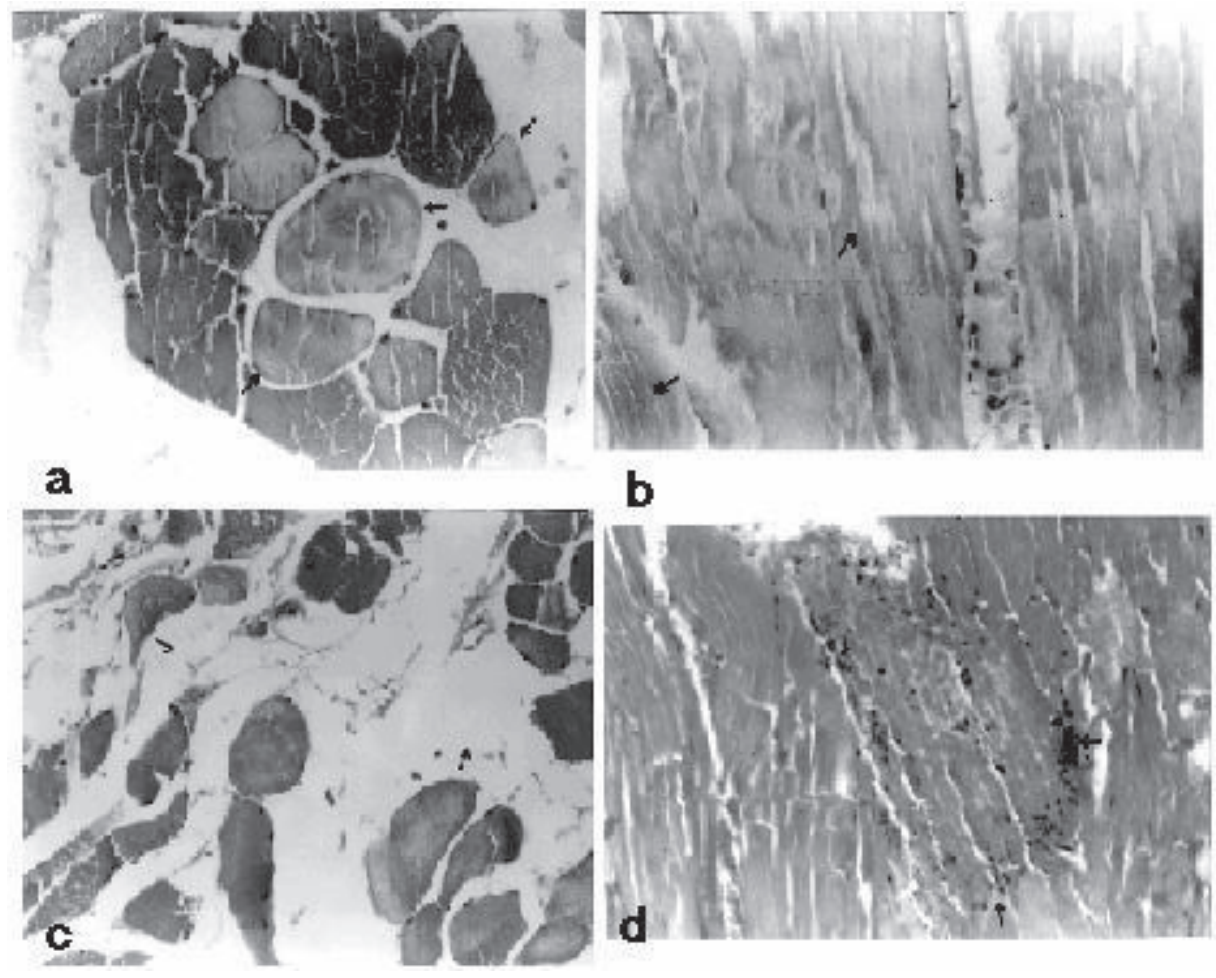

b

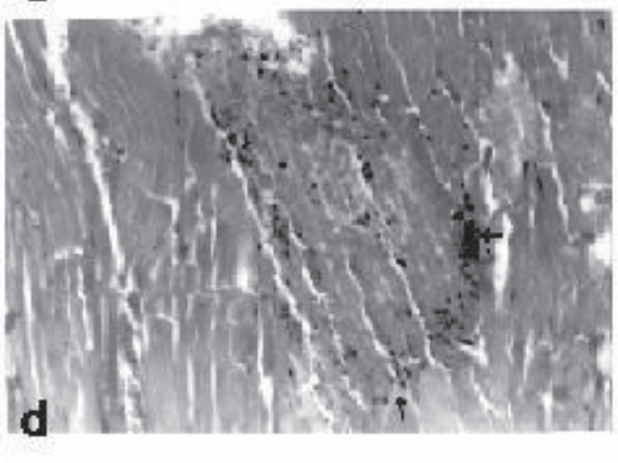

Figure 4. The figure shows (a) ring formation, (b) splitting formation, (c) interstitial edema, (d) neutrofil cell infiltration in control groups (the arrows were depicted pathological changes) $\times 400 \mathrm{HE}$.

showed that a period over $2 \mathrm{~h}$ of reperfusion is enough to establish the muscular lesion (40-42).

Most study was made relation to administration time of drugs in order to decrease $\mathrm{I} / \mathrm{R}$ damage (17-19). These studies were carried out in which antioxidants were given before ischemia. However, antioxidant agents were injected before reperfusion in other study (43). In a study, Feller showed that SOD and dimethylsulfoxide $\left(\mathrm{OH}^{-}\right.$radical scavenger $)$ given before reperfusion and decreased reperfusion injury, and in late term, the muscle functions were excellent (44). We administrated antioxidant agents to the drug groups before ischemia in our study.

FRs are normal by-products of cellular metabolic processes. The human body has a complex antioxidant defense system that includes the antioxidant enzymes (SOD, GPX and CAT) and nonenzymatic antioxidant components such as glutathione, a-tocopherol, ascorbic acide, and b-carotene. These prevent the initiation or propogantation of free radical chain reactions. Post-ischemic reperfusion injury is associated with the generation of FRs which damage cellular components and initiate the lipid peroxidation process. In many studies, antioxidant activity was tried to be shown through biochemical enzyme studies in addition to histopathological studies. We examined that the vitamin combinations given 3 days before the ischemia and allopurinol given 2 days before the ischemia for decreased $\mathrm{I} / \mathrm{R}$ damage, both histopathological and biochemical. We could not find any report showing the effect of ascorbic acide, alpha-tocopherol, and allopurinol on recuding $\mathrm{I} / \mathrm{R}$ injury in lower extremity muscle of rabbit as enzymatic and biochemically.

SOD is an enzyme which catalyses the transformation of the $\mathrm{O}_{2}{ }^{-}$into $\mathrm{H}_{2} \mathrm{O}_{2}$, and it is one of the primary and significant defensive systems against oxidative damage. The physiological function of this enzyme is to protect the cells of oxygen against FRs harmful effects $(45,46)$. When oxidant stress increases in organism, SOD enzyme levels increase (45). The function of CAT is to divide $\mathrm{H}_{2} \mathrm{O}_{2}$ into $\mathrm{O}_{2}{ }^{-}$and $\mathrm{H}_{2} \mathrm{O}$ by participating into the reaction with $\mathrm{H}_{2} \mathrm{O}_{2}$. Through this, it prevents the formation of $\mathrm{OH}^{-}$radicals, which are more toxic. Criado found that CAT enzyme levels increased in 30 minutes after I/R damage (47). For GPx catalyses $\mathrm{H}_{2} \mathrm{O}_{2}$ and lipid hydroperoxidase, it protects to cellular membranes from damage, prevents the start and development of lipid peroxidation. Lin showed in a myocardial ischemia reperfusion injury model found that GPx levels increased with the antioxidant 
agent (48). In our study, SOD, CAT and GPx levels were increased in the treatment groups compared to control group $(p<0.05)$. Although there was no significant different between treatment groups, the increase of the enzymes levels was higher in group IV than group II and III.

The end production of lipid peroxidation includes aldehydes, hydrocarbon gases, and MDA. It is good markers for increased systemic oxidative stress (48). MDA levels indicate the amount of cellular damage secondary to lipid peroxidation and has been widely adopted as a measure of free radical formation. Lipid peroxidation can cause changer leading to the deaths of cells. Feng found that MDA increase depended on FR appearance (49). A significant elevation of MDA level after the $30 \mathrm{~min}$ of ischemia and $45 \mathrm{~min}$ of reperfusion was observed in tissues (50). In our study, the MDA levels had significantly increased after ischemia reperfusion in the control group, because of the high level of hydroxyl radicals. In the antioxidant treatment groups, the levels were found have decreased, which may show the effects of antioxidant medication on limiting ischemia reperfusion injury.

XO plays an important role in I/R injury $(6,51)$. There is evidence that $\mathrm{XO}$ levels are elevated during ischemia (52). $\mathrm{XO}$ is the first-known $\mathrm{O}_{2}^{-}$radical source (16). During ischemia, adenosine triphosphate is degraded to hypoxanthine and xanthine dehydrogenase is converted to XO. During reperfusion, $\mathrm{XO}$ catalyzes the conversion of hypoxanthine to uric acid with release of the $\mathrm{O}_{2}{ }^{-}$ radical. Hammerman showed that lipid peroxidation was prevented in the group together with the decrease in XO activity (53). Allopurinol is considered to be an XO inhibitor. Smith found that I/R injury were decreased with tungsten and allopurinol (54). In our study, there were significant differences in the levels of XO between treatment groups and control group $(p<0.05)$. Moreover, the decrease was highest in group III and IV administrated allopurinol.

Ascorbic acide is a powerful antioxidant agent. It is a critical component of the oxidant shield in skeletal muscle, being actively accumulated by muscle endothelium (55) According to Niki et al. (20), ascorbic acide has an antioxidant effect of the superoxide and hydrophilic radicals. It also acts on limiting lipidic peroxidation and scavenges reactive oxidants produced immediately after reperfusion (21). In our study, in group II and IV, which was used ascorbic acide, decreased level of XO and MDA enzyme and increased antioxidant enzymes (SOD, CAT and GPx) levels, and these results were supported with histopathological findings. Alpha-tocopherol is an antioxidant, and is protector against FRs. The preventive effects of alpha-tocopherol has been demonstrated in different experimental models $(56,57)$. It protects cell membrane from oxidative damage and lipid peroxidation (57). Allopurinol, a specific inhibitor of the enzyme XO, blocks the synthesis of xanthine from hypoxanthine and therefore avoids the formation of the free radical superoxide. The studies showed that it is decrease the level of FRs production and reduce the tissue injury associated with $\mathrm{I} / \mathrm{R}$ injury $(23,58)$. It is not only a potent inhibitor of XO but may also be an agent that improves ischemia-induced mitochondrial dysfunction $(14,58)$.

Our data show that FR overproduction induced by I/R causes lipid peroxidation of rabbit skeletal muscle. Administration of ascorbic acide, alphatocopherol (before 3 days) and allopurinol (before 2 days) skeletal I/R decreased MDA and XO levels and increased in SOD, CAT and GPx enzyme activities in the skeletal muscle and this result was suggested with hystopathological results. Results of this study show that prophylactic administration of ascorbic acide, alpha-tocopherol and allopurinol ischemia condition prevents reperfusion injuries by eliminating oxygen radicals and inhibiting lipid peroxidation. Besides, the combination of ascorbic acide, alpha-tocopherol and allopurinol may be sufficient to more efficiently prevent subsequent oxidative stress in the tissues and improve their function after $\mathrm{I} / \mathrm{R}$.

\section{References}

[1] Nanobashvili, J., Neumayer, C., Fuegl, A. et al. 2003. Development of 'no-reflow' phenomenon in ischemia/reperfusion injury: failure of active vasomotility and not simply passive vasoconstriction. Eur. Surg. Res., 35:417-4.

[2] Chander, V. and Chopra, K. 2006. Protective effect of nitric oxide pathway in resveratrol renal ischemia-reperfusion injury in rats. Arch. Med. Res., 37:19-26.

[3] Waters, S., Fae, A., Gondalia, J. et al. 2004. Effects of pretreatment with a xanthine oxidase inhibitor on free radical levels during carotid endarterectomy. Free Radic. Res., 38:283-93.

[4] Draper, H.H. and Hadley, M. 1990. Malondialdehyde determination as index of lipid peroxidation. Methods Enzymol., 186:421.

[5] Ozcan, A.V., Sacar, M., Aybek, H. et al. 2007. The effects of iloprost and vitamin $\mathrm{C}$ on kidney as a remote organ after ischemia/reperfusion of lower extremities. J. Surg. Res., 140:20-6. 
[6] Inal, M., Altinisik, M. and Bilgin, M.D. 2002. The effect of quercetin on renal ischemia and reperfusion injury in the rat. Cell. Biochem. Funct., 20:291-6.

[7] Engerson, T.D., McKelvey, T.G., Rhyne, D.B., Boggio, E.B., Snyder, S.J. and Jones, H.P. 1987. Conversion of xanthine dehydrogenase to oxidase in ischemic rat tissues. J. Clin. Invest, 79:1564-70.

[8] McCord, J.M. 2000. The evolution of free radicals and oxidative stress. Am. J. Med., 108:652-9.

[9] Concannon, M.J., Kester, C.G., Welsh, C.F. et al. 1992. Patterns of freeradical production after tourniquet ischemia: implications for the hand surgeon. Plast Reconstr. Surg., 89:846-52.

[10] Kearns, S.R., Daly, A.F., Sheehan, K., Murray, P., Kelly, C. and Bouchier-Hayes, D. 2004. Oral vitamin C reduces the injury to skeletal muscle caused by compartment syndrome. J. Bone Joint Surg. Br., 86:906-11.

[11] Armour, J., Tyml, K., Lidlington, D. and Wilson, J.X. 2001. Ascorbate prevents microvascular dysfunction in the skeletal muscle of the septic rat. J. Appl. Physiol., 90:795-803.

[12] Kearns, S.R., Kelly, C.J., Barry, M. et al. 1999. Vitamin C reduces ischaemia-reperfusioninduced acute lung injury. Eur. J. Vasc Endovasc Surg., 17:533-6.

[13] Yagmurdur, M.C., Ozdemir, A., Ozenc, A. and Kilinc, K. 2003. The effects of alpha-tocopherol and verapamil on mucosal functions after gut ischemia/reperfusion. Turk J. Gastroenterol. $14: 26-32$.

[14] Isik, N., Berkman, M.Z., Pamir, M.N., Kalelioglu, M. and Sav, A. 2005. Effect of allopurinol in focal cerebral ischemia in rats: an experimental study. Surg. Neurol., 64:Suppl 2:S5-10.

[15] Jeon, B.R., Yeom, D.H. and Lee, S.M. 2001. Protective effect of allopurinol on hepatic energy metabolism in ischemic and reperfused rat liver. Shock, 15:112-7.

[16] Lindsay, T., Romaschin, A. and Walker, P.M. 1989. Free radical mediated damage in skeletal muscle. Microcirc Endothelium Lymphatic, 5:57-70.

[17] Punz, A., Nanobashvili, J., Neumayer, C. et al. 1999. Multivitamin administration before ischemia reduces ischemia-reperfusion injury in rabbit skeletal muscle. Clin. Nutr., 18:219-26.

[18] Akgun, S., Tekeli, A., Isbir, S.C., Civelek, A., Ak, K. and Sirvanci, S. 2004. FK506 to prevent lung injury after hindlimb ischemia and reperfusion in a rat model: an electron microscopic study. Surg. Today, 34:678-84.

[19] Tanaka, M., Terry, R.D., Mokhtari, G.K., Inagaki, K., Koyanagi, T. and Kofidis, T. 2004. Suppression of graft coronary artery disease by a brief treatment with a selective epsilon PKC activator and a deltaPKC inhibitor in murine cardiac allografts. Circulation, 14:110 (11 Suppl 1): II194-99.

[20] Niki, E. 1991. Action of ascorbic acid as a scavenger of active and stable oxygen radicals. Am. J. Clin. Nutr., 54:1119S-1124S.

[21] Higa, O.H., Parra, E.R., Ab'Saber, A.M., Farhat, C., Higa, R. and Capelozzi, V.L. 2007. Protective effects of ascorbic acid pretreatment in a rat model of intestinal ischemia-reperfusion injury: a histomorphometric study. Clinics, 62:315-20.

[22] Seo, M.Y. and Lee, S.M. 2002. Protective effect of low dose of ascorbic acid on hepatobiliary function in hepatic ischemia/reperfusion in rats. J. Hepatol., 36:72.

[23] Lee, W.Y. and Lee, S.M. 2006. Synergistic protective effect of ischemic preconditioning and allopurinol on ischemia/reperfusion injury in rat liver. Biochem. Biophys. Res. Commun. 349:1087-93

[24] Akgur, F.M., Klinic, K., Aktug, T. and Olguner, M. 1994. The effect of allopurinol pretreatment before detorting testicular torsion. J. Urol., 151:1715-7.

[25] Nakamura, M., Ozaki, M., Fuchinoue, S., Teraoka, S. and Ota, K. 1997. Ascorbic acid prevents ischemic-reperfusion injury in the rat small intestine. Transplant Int., 10:89-95.

[26] Gupta, Y.K. and Sharma, M. 2001. Reversal of pyrogallol-induced delay in gastric emptying in rats by ginger (Zingiber officinale). Methods Find Exp. Clin. Pharmacol., 23:501-3.
[27] Cadenas, S., Lertsiri, S., Otsuka, M., Barja, G. and Miyazawa, T 1996. Phospholipid hydroperoxides and lipid peroxidation in liver and plasma of ODS rats supplemented with alpha-tocopherol and ascorbic acid. Free Radic. Res., 24:485-93.

[28] Hoballah, J.J., Mohan, C.R., Schipper, P.H., Chalmers, R.T., Corry, D.C. and Corson, J.D. 1996. Rabbit rectus femoris muscle for ischemiareperfusion studies: an improved model. J. Surg. Res., 66:21-4.

[29] Sun, Y., Oberley, L.W. and Li, Y. 1988. A simple method for clinical assay of superoxide dismutase. Clin. Chem., 34:497-500.

[30] Cohen, G., Dembiec, D. and Marcus, J. 1970. Measuement of catalase activity in tissue extracts. Anal. Biochem., 34:30-8.

[31] Beutler, E. 1973. Red cell metabolism. A manuel of biocemical methods. New York: In Grune and Stratton.74.

[32] Ohkawa, H., Ohishi, N. and Yagi, K. 1979. Assay for lipid peroxides in animal tissues by thiobarbituric acid reaction. Anal. Biochem., 95:351-8.

[33] Hashimato, S.A. 1974. New spectrophotometric assay method of xanthine oxidase in crude tissue homogenate. Anal. Biochem., 62:425-35.

[34] Hickey, M.J., Hurley, J.V., Angel, M.F. and O’brien, B.M. 1992. The response of the rabbit rectus femoris muscle to ischemia and reperfusion. J. Surg.. Res., 53:369-377.

[35] Belkin, M., Lamorte, W.I., Wright, J.G. and Hobson, R.W. 1989. 2nd. The role of leucocytes in the pathophysiology of skeletal muscle ischemic injury. J. Vasc. Surg., 10:14-9.

[36] Mohler, L.R., Pedowitz, R.A., Ohara, W.M. et al. 1996. Effects of an antioxidant in a rabbit model of tourniquet induced skeletal muscle ischemia-reperfusion injury. J. Surg. Res., 60:23-8.

[37] Bushell, A., Klenerman, L., Davies, H. et al. 1996. Ischemia reperfusion-induced muscle damage: protective effect of corticosteroids and antioxidants in rabbits. Acta. Orthop. Scand, 67:393-8

[38] Harris, K., Walker, P.M., Mickle, D.A.G. et al. 1986. Metabolic response of skeletal muscle to ischemia. Am. J. Physiol., 250:213-20.

[39] Makitie, J. and Teravainen, H. 1977. Histochemical studies of striated muscle after temporary ischemia in the rat. Acta. Neuropathol., 37:247-53.

[40] Appell, H.J., Duarte, J.A., Gloser, S. et al. 1997. Administration of tourniquet. II. Prevention of postischemic oxidative stres can reduce muscle edema. Arch. Orthop. Trauma Surg., 116:101-5.

[41] Santavirta, S., Luoma, A. and Arstila, A.U. 1979. Morphological and biochemical changes in rabbit striated muscle of after experimental tourniquet ischemia. Res. Exp. Med., 174:245-51.

[42] Strock, P.E. and Majno, G. 1969. Vascular responses to experimental tourniquet ischemia. Surg. Gynecol. Obstet., 129:309-18.

[43] Bozkurt, A.K. 2002. Alpha-tocopherol (Vitamin E) and iloprost attenuate reperfusion injury in skeletal muscle ischemia/reperfusion injury. J. Cardiovasc Surg. (Torino), 43:693-6.

[44] Feller, A.M., Roth, A.C., Russell, R.C., Eagleton, B., Suchy, H. and Debs, N. 1989. Experimental evaluation of oxygen free radical scavengers in the prevention of reperfusion injury to skeletal muscle. Ann. Plast Surg., 22:321-31.

[45] Seven, A. and Candan, G. 1996. Antioxidant defences systems. Cerrahpaşa J. Med., 27.

[46] Kanko, M., Maral, H., Akbas, M.H. et al. 2005. Protective effects of clopidogrel on oxidant damage in a rat model of acute ischemia. Tohoku J. Exp. Med., 205:133-9.

[47] Garcia-Criado, F.J., Palma-Vargas, J.M., Valdunciel-Garcia, J.J., Gomez-Alonso, A., Srivastava, O. and Ezrin, A. 1997. Sulfo-Lewis(x) diminishes neutrophil infiltration and free radicals with minimal effect on serum cytokines after liver ischemia and reperfusion. J. Surg. Res., 70:187-94. Erratum in: J. Surg. Res., 73:95.

[48] Lin, L.N., Wang, W.T. and Xu, Z.J. 1997. Clinical study on ligustrazine in treating myocardial ischemia and reperfusion injury. Zhongguo Zhong Xi Yi Jie He Za Zhi, 17:261-3.

[49] Feng, F. 1990. Biochemical metabolism and oxygen free radical changes following ischemic and reperfused injured limbs. An experimental study. Zhonghua Wai Ke Za Zhi, 28:693-6. 
[50] Campos, R., Maureira, F., Garrido, A. and Valenzuela, A. 1993. Different glutathione redox status and lipid peroxidation in the cortex and the medulla of the rat kidney subjected to ischemia-reperfusion stress. Comp. Biochem. Physiol. B., 105:157-63.

[51] Joannidis, M., Gstraunthaler, G. and Pfaller, W. 1990. Xanthine oxidase: evidence against a causative role in renal reperfusion injury. Am. J. Physiol., 258:F232-F236.

[52] Engerson, T.D., McKelvey, T.G., Rhyne, D.B., Boggio, E.B., Snyder, S.J. and Jones, H.P. 1987. Conversion of xanthine dehydrogenase to oxidase in ischemic rat tissues. J. Clin. Invest, 79:1564-70.

[53] Hammerman, C., Goldschmidt, D., Caplan, M.S., Kaplan, M., Schimmel, M.S. and Eidelman, A.I. 1999. Amelioration of ischemiareperfusion injury in rat intestine by pentoxifylline-mediated inhibition of xanthine oxidase. J. Pediatr Gastroenterol. Nutr., 29:69-74.

[54] Smith, J.K., Carden, D.I. and Korthuis, R.J. 1987. Role of xanthine oxidase in post ischemic microvascular injury in skeletal muscle. Am. J. Physiol., 257:1782-9.
[55] Wilson, J.X., Dixon, S.J., Yu, J., Nees, S. and Tyml, K. 1996. Ascorbate uptake by microvascular endothelial cells of rate skeletal muscle. Microcirculation, 3:211-21.

[56] Demirbas, A., Bozoklu, S., Ozdemir, A. and Haberal, M. 1993. Effect of alpha tocopherol on the prevention of reperfusion injury caused by free oxygen radicals in the canine kidney autotransplantation model. Transplant Proc., 25:2274.

[57] Hsiao, G., Lee, J.J., Chen, Y.C. et al. 2007. Neuroprotective effects of PMC, a potent alpha-tocopherol derivative, in brain ischemiareperfusion: reduced neutrophil activation and anti-oxidant actions. Biochem. Pharmacol., 73:682-93.

[58] Canbaz, S., Duran, E., Ege, T., Sunar, H., Cikirikcioglu, M. and Acipayam, M. 2003. The effects of intracoronary administration of vitamin $\mathrm{E}$ on myocardial ischemia-reperfusion injury during coronary artery surgery. Thorac Cardiovasc Surg., 51:57-61. 